\title{
CHONDROSARCOMA OF METACARPAL- A RARE CASE PRESENTATION
}

\section{P. V. Pugalenthi' ${ }^{1}$ K. Ravichandran ${ }^{2}$, S. Arun Kumar ${ }^{3}$}

1 Professor and HOD, Department of Orthopaedics, Madurai Medical College, Madurai.

${ }^{2}$ Assistant Professor, Department of Orthopaedics, Madurai Medical College, Madurai.

${ }^{3}$ Postgraduate Student, Department of Orthopaedics, Madurai Medical College, Madurai.

\section{ABSTRACT}

\section{BACKGROUND}

Chondrosarcoma, a malignant bone tumour constitutes about $9 \%$ of primary bone malignancies. Common in locations like proximal femur, proximal humerus and pelvis, rarely it can occur in hand. Here, we present a case of chondrosarcoma of the second metacarpal bone, because of its rarity.

\section{KEYWORDS}

Chondrosarcoma, Malignant Tumour, Metacarpal.

HOW TO CITE THIS ARTICLE: Pugalenthi PV, Ravichandran K, Kumar SA. Chondrosarcoma of metacarpal- a rare case presentation. J. Evolution Med. Dent. Sci. 2017;6(14):1160-1162, DOI: 10.14260/Jemds/2017/251

\section{BACKGROUND}

Chondrosarcoma, a malignant bone tumour constitutes about $9 \%$ of primary bone malignancies. Common in locations like proximal femur, proximal humerus and pelvis, rarely it can occur in hand. Here, we present a case of chondrosarcoma of the second metacarpal bone because of its rarity.[1]

\section{Case Report}

A 65-year-old male presented with complaints of swelling over dorsum of dorsum of right hand for past 2 years associated with pain. Swelling was spontaneous, insidious in onset, gradually progressive with pain for last 6 months. There were no constitutional symptoms. Clinically, patient had swelling of size $10^{*} 5^{*} 2 \mathrm{~cm}$ extending from lateral border of $2^{\text {nd }}$ metacarpal to medial border of $3^{\text {rd }}$ metacarpal, hard in consistency and immobile. Metacarpal could not be palpated separately off the swelling. Skin over swelling was shiny with dilated veins. Movements of $2^{\text {nd }}$ metacarpophalangeal joint were restricted.

Radiograph of the hand showed an expansile lesion of entire $2^{\text {nd }}$ metacarpal with cortical destruction and soft tissue shadow. Lesion was abutting third metacarpal. MRI scan confirmed findings of cortical break and soft tissue mass.

Investigations revealed no metastasis and no other similar lesions elsewhere in body. We proceeded with an open biopsy, which showed low-grade chondrosarcoma. Based on clinical, radiological and histopathological findings, we made a diagnosis of chondrosarcoma.

The patient was educated about tumour and explained about treatment plan and recurrence rates. After an informed consent from patient, we decided to do radical resection of tumour. The entire second and third metacarpal was removed with surrounding muscles and the biopsy track. The resected specimen was examined histopathologically.

Financial or Other, Competing Interest: None.

Submission 20-12-2016, Peer Review 02-02-2017,

Acceptance 08-02-2017, Published 16-02-2017.

Corresponding Author:

Dr. S. Arun Kumar,

Postgraduate Student,

Department of Orthopaedics,

Madurai Medical College, Madurai.

E-mail: akonline02@gmail.com

DOI: $10.14260 /$ jemds $/ 2017 / 251$

\section{(c) $(1)$}

It showed bony trabeculae entrapped by lobules of chondrocytes with chondroid matrix exhibiting pleomorphism, hyperchromasia, mitosis, area of myxoid change and necrosis consistent with well-differentiated chondrosarcoma. The margins of tumour with surrounding soft tissues were clear. The patient was informed that data concerning the case would be submitted for publication and he consented.

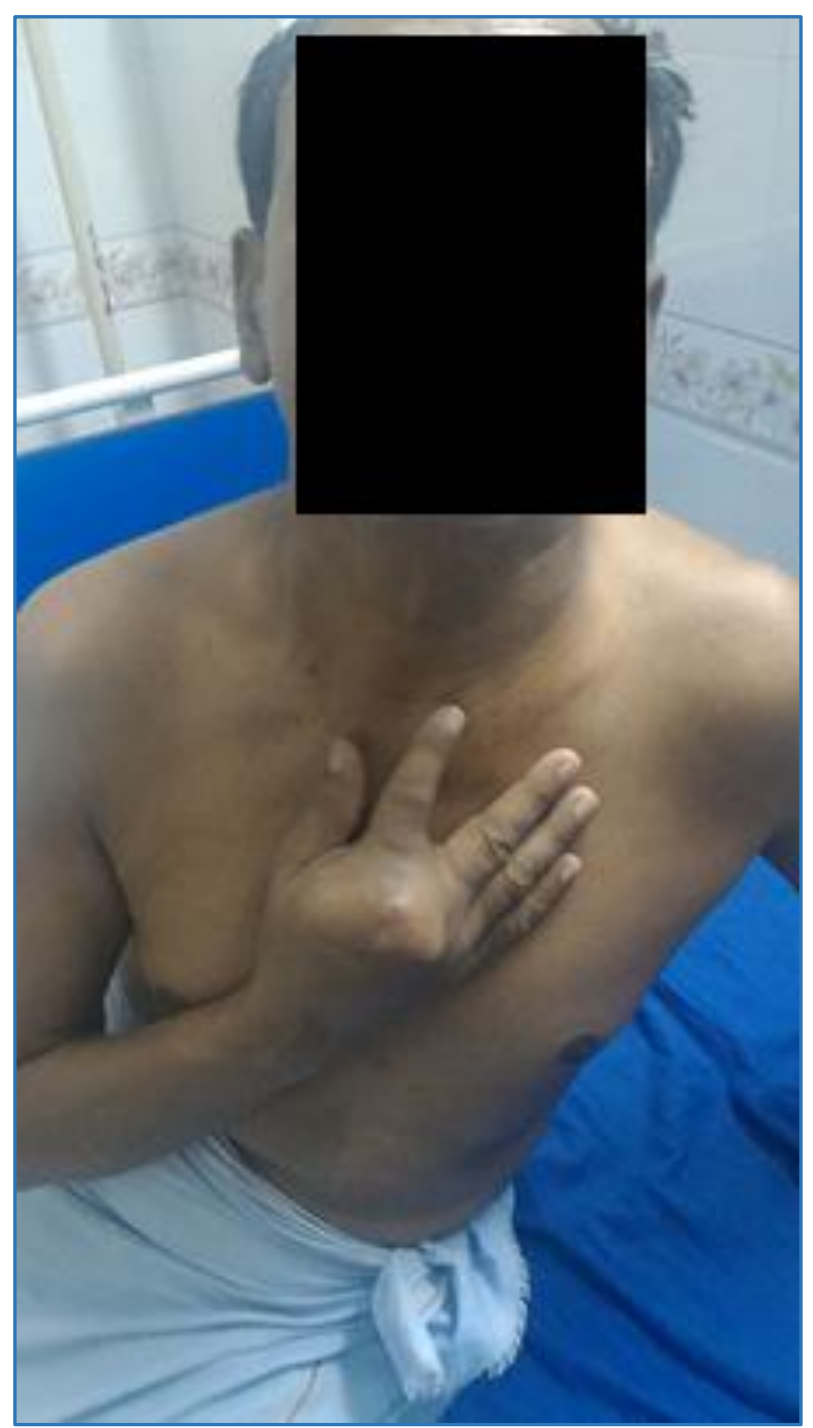




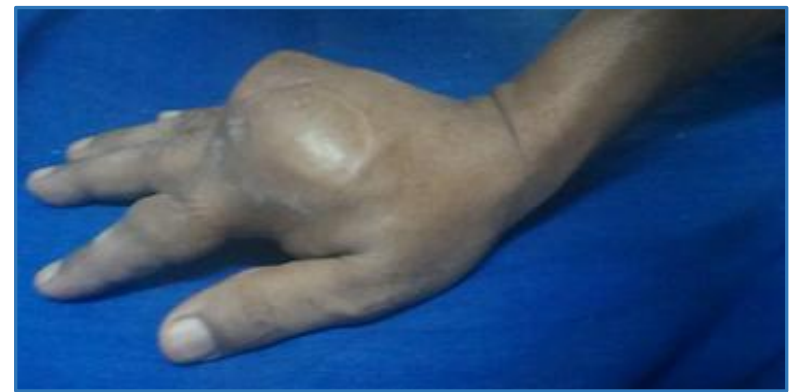

Clinical Picture

\section{Radiological Findings}

An expansile lesion of the entire second metacarpal with cortical destruction and encroaching $3^{\text {rd }}$ metacarpal head and base of proximal phalanx with pathological fracture of $2^{\text {nd }}$ metacarpal.

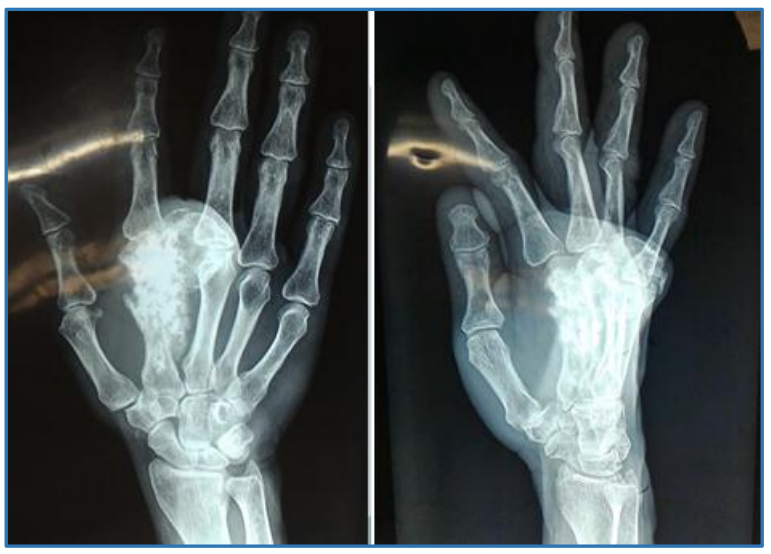

Pre-operative X-Ray
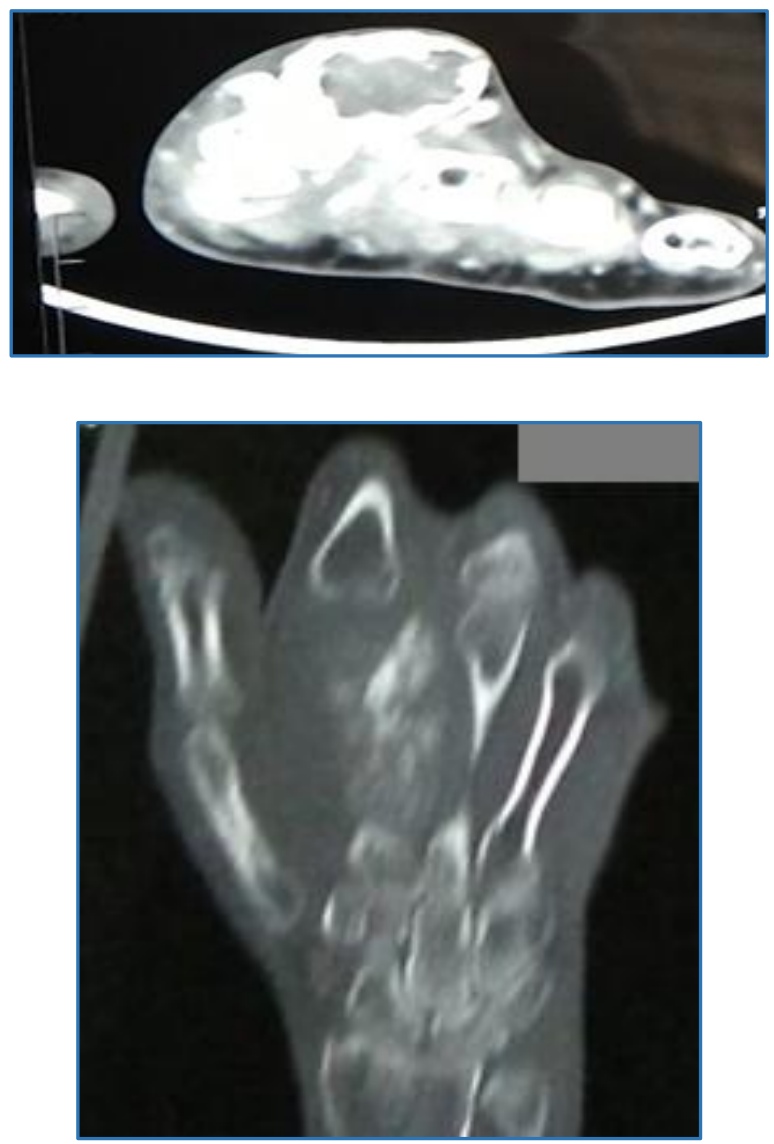

Preoperative CT Image
The cartilage tumour has surrounded the normal trabeculae, producing a cartilage matrix with increased cellularity and enlarged nuclei, typical of chondrosarcoma.

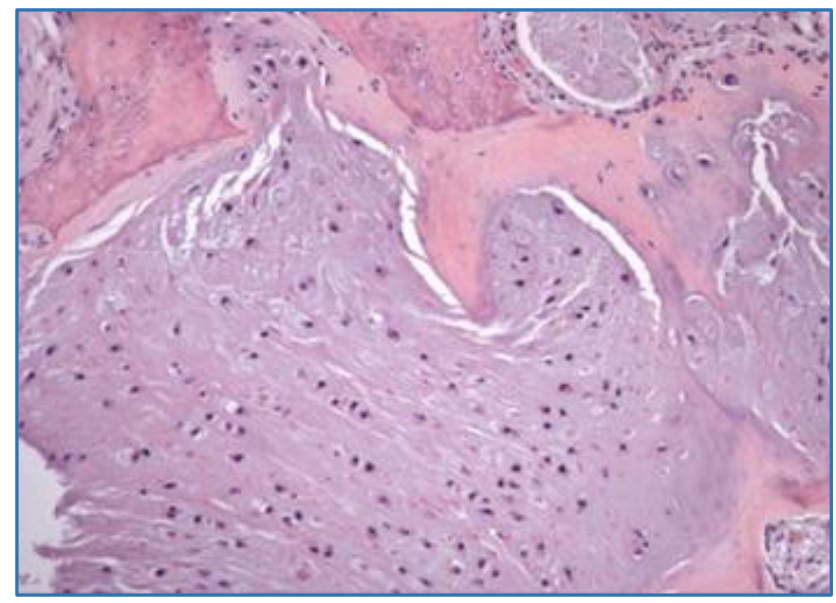

Histology

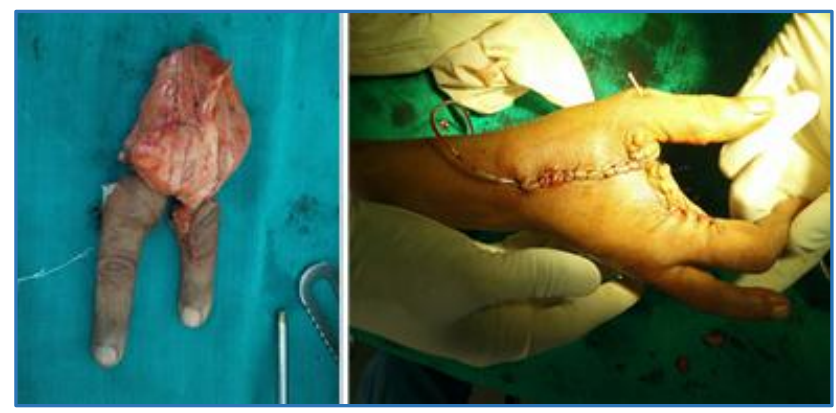

Macroscopic Appearance

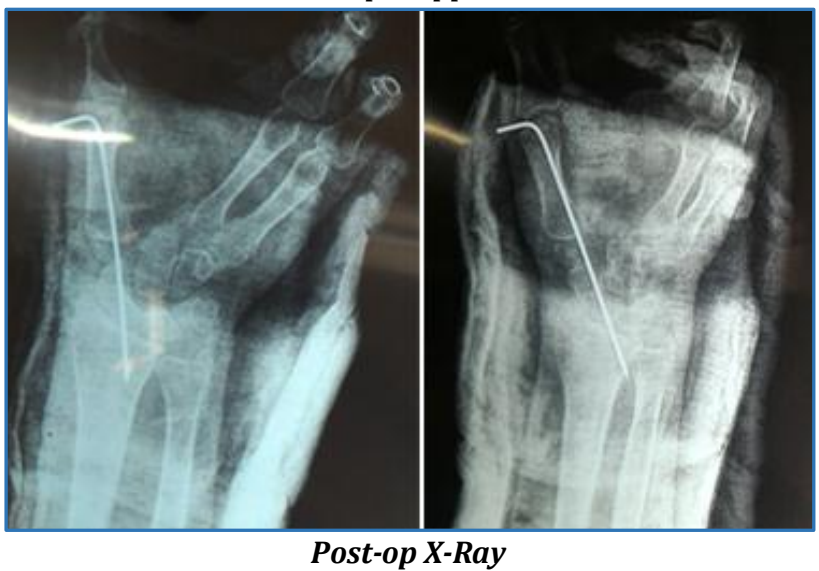

\section{DISCUSSION}

Primary chondrosarcoma is rare in hand with frequency of only $1.5-3.2 \%$ of all chondrosarcomas. Phalangeal bones are affected in $60 \%$ of cases, metacarpals in about $40 \%$.[2] $^{[2]}$ Chondrosarcoma are slow growing and symptoms can be present for years before patient seeks medical attention. Similar to enchondroma it is a lesion arising in medullary cavity with irregular matrix calcification, but chondrosarcomas have a more aggressive appearance with bone destruction, cortical erosion, periosteal reaction and rarely a soft tissue mass. Histologically, chondrosarcomas are composed of malignant cells with abundant cartilaginous matrix, hypercellularity, plump nuclei, binucleate cells, permeative pattern and entrapment of bony trabeculae. Chondrosarcoma is often separated into three histological 
grades: low (Grade 1), medium (Grade 2) and high (Grade 3).[3] The higher the grade, the more likely it is that the tumour will metastasise.

The treatment of low-grade chondrosarcoma is controversial with good results after extended curettage and the use of intraoperative adjuvant treatments. [4] Resection is the treatment of choice for the rest. For resection a wide operative margin is suggested, as it will reduce prevalence of local recurrence. Generally, chondrosarcoma does not infiltrate the surrounding extraosseous tissues and by resecting the involved bone with a small cuff of surrounding soft tissues that originate from involved bone, an adequate margin is obtained. Chemotherapy has no role in treatment of conventional chondrosarcoma.[5] Radiotherapy likewise has limited role in treating surgically inaccessible areas.

In our patient, the tumour was involving the entire metacarpal with surrounding muscles, precluding curettage and salvation of the metacarpal, hence ray amputation of $2^{\text {nd }}$ and $3^{\text {rd }}$ fingers with K-wire stabilisation of Thumb was done. The purpose of this study was not to give a description of chondrosarcoma and its clinicopathologic presentation, but to present the rarity of this tumour in the metacarpal.

\section{CONCLUSION}

In our patient, the tumour was involving the entire metacarpal with surrounding muscles, precluding curettage and salvation of the metacarpal; hence, ray amputation of 2nd and 3rd fingers with $\mathrm{K}$-wire stabilisation of Thumb was done. The purpose of this study was not to give a description of chondrosarcoma and its clinicopathologic presentation, but to present the rarity of this tumour in the metacarpal.

\section{REFERENCES}

[1] Nelson DL, Abdul-Karim FW, Carter JR, et al. Chondrosarcoma of small bones of the hand arising from enchondroma. J Hand Surg 1990;15(4):655-9.

[2] Gottschalk RG, Smith RT. Chondrosarcoma of the hand. J Bone Joint Surg 1963;45(1):141-50.

[3] Roberts $\mathrm{PH}$, Price $\mathrm{CH}$. Chondrosarcoma of the bones of the hand. J Bone Joint Surg 1977;59(2):213-21.

[4] Döhler R, Heinemann G, Busanny-Caspari W, et al. Chondrosarcoma of the first metatarsal-primary or secondary to enchondroma. Arch Orthop Trauma Surg 1979;95(3):221-5.

[5] Culver JE, Sweet DE, Mccue FC. Chondrosarcoma of the hand arising from a pre-existent benign solitary enchondroma. Clin Orthop 1975;113:128-31. 